\title{
Laser Welding of TC4 Ti Alloy and 304 Stainless Steel with Different Joining Modes
}

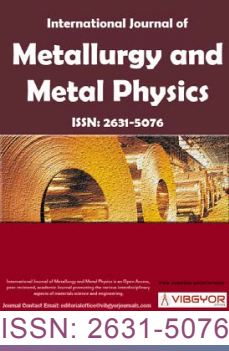

\section{Yan Zhang ${ }^{1 *}$, Yan Kun Chen ${ }^{1}$, Jian Ping Zhou', Da Qian Sun ${ }^{2}$ and Hong Mei Lí}

${ }^{1}$ School of Mechanical Engineering, Xinjiang University, China

${ }^{2}$ Key Laboratory of Automobile Materials, School of Materials Science and Engineering, Jilin University, China

\begin{abstract}
In this paper, Nd: YAG laser welding of TC4 Ti alloy and SUS301L stainless steel (SS) dissimilar metal material was carried using $\mathrm{Ni}$ interlayer by laser offset. The laser was focused on the SS side of the joint, which joined the SS and Ni interlayer by fusion welding. At SS-Ni interface, a weld zone was formed due to dilution of the $\mathrm{Ni}$ and mixing with the $\mathrm{SS}$. At the $\mathrm{Ti}$ alloy- $\mathrm{Ni}$ interface, a metallurgical reaction was responsible for joining. The presence of unmelted $\mathrm{Ni}$ interlayer ensured that crack free welds were obtained and no brittle Ti-Fe intermetallics were observed. Tensile strength of the joint can reach to $178 \mathrm{MPa}$.
\end{abstract}

Keywords

TC4 Ti alloy, 304 stainless steel, Welding, Microstructure, Filler metal

\section{Introduction}

Ti alloy has been broadly applied in various industrial fields as characterized by high strength, good toughness, low density, high temperature resistance and good corrosion resistance [1]. Yet its application has been restrained by the high cost of $\mathrm{Ti}$ alloy, poor weldability and processing performance, poor creep resistance. Stainless steel (abbreviated as SS) was the most commonly used structural material, with numerous excellent properties, such as weldability, wear resistance, mechanical properties, and relatively low cost [2]. Recently, the dissimilar joint of Ti alloy and SS has been highly demanded in aerospace and nuclear industries [3]. However, owing to the poor metallurgical compatibility and significant mismatch in physical and mechanical properties, the joining of Ti alloy to SS is facing to a great difficulty [4-6]. Direct fusion welding of $\mathrm{Ti}$ alloy and SS can form various intermetallics, such as TiFe and $\mathrm{TiFe}_{2}$, etc. These highly brittle Ti-Fe intermetallics make conventional fusion-welded joints cracked spontaneously. Therefore, the weld was very brittle and easy to crack under residual stress.

The general method to address this problem is to use interlayer between Ti alloy and SS to prevent the formation of brittle Ti-Fe intermetallics. The interlayers such as $\mathrm{Cu}, \mathrm{Ag}, \mathrm{Ni}, \mathrm{Al}$ and $\mathrm{Mg}$ have been employed to restrain the formation of Ti-Fe intermetallics during welding [7-9]. The tensile strength of pulsed laser welding dissimilar joint of TC4 Ti alloy to $301 \mathrm{~L}$ SS using $\mathrm{Cu}$ as an interlayer reached

*Corresponding author: Yan Zhang, School of Mechanical Engineering, Xinjiang University, Wulumuqi 830000, China

Accepted: May 30, 2020; Published: June 01, 2020

Copyright: (c) 2020 Zhang Y, et al. This is an open-access article distributed under the terms of the Creative Commons Attribution License, which permits unrestricted use, distribution, and reproduction in any medium, provided the original author and source are credited.

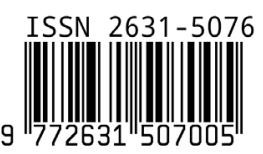

Zhang et al. Int J Metall Met Phys 2020, 5:055 
$340 \mathrm{MPa}$, as found by XiaoYan Gu, et al. [10]. Using $\mathrm{Cu}$ as interlayer can greatly reduce the brittleness of the weld. As their studies suggest, the amount of brittle Ti-Fe intermetallics decreased in the joint. Yet brittle $\mathrm{Cu}$-Ti intermetallics, such as $\mathrm{CuTi}_{2}$ were formed. Accordingly, it is concluded that Ti-Fe intermetallics are inevitably formed in the welding if the interlayer is fully melted. Accordingly, the $\mathrm{Ti}$ and Fe elements will react in the weld pool, producing Ti-Fe intermetallics in the welding as long as the interlayer is completely melted. Researchers are trying to minimize the mixing of matrix materials to prevent the formation of these brittle phases, indeed even low mixing cannot avoid the formation of brittle Ti-Fe intermetallics. By one pass welding, XiaoYan Gu, et al. [11] studied pulsed laser welding of SUS 301L SS to TC4 Ti alloy via pure Nb interlayer. The joint was formed with one welding zone and a reaction layer separated by residual unmelted $\mathrm{Nb}$ interlayer. The unmelted $\mathrm{Nb}$ interlayer served as a diffusion barrier between $\mathrm{Ti}$ and $\mathrm{Fe}$ to restrain the formation of Ti-Fe intermetallics. The mechanical performance of the joint was determined by the reaction layer at the $\mathrm{Nb}$-SS interface with a tensile strength of $370 \mathrm{MPa}$. Yet Fe-Nb intermetallics were formed in the reaction layer, which decreased the mechanical property of the joints. How to ensure the quality of the joint is mainly to suppress or avoid the formation of Ti-Fe intermetallic compounds, we should solve these problems. However, the appropriate process parameters and the location of the laser beam spot must be selected to control the formation of the reaction layer in joint. Therefore, this process is too cumbersome and not suitable for industrial production.

Moreover, solid-state welding can eliminate the problems in the direct fusion welding because the base metals remain in the solid state during joining and many successful examples have been reported [12-14]. As the noted results suggest, these two dissimilar materials can be joined by using diffusion bonding [12], friction [13] and explosive welding [14]. They have concluded that at low loads for- mation of intermetallics could be totally avoided. However, the service conditions may make particular processes unsuitable. The diffusion process needs a long time to implement in general. Taking high temperature applications for example, brazing cannot be candidate. Furthermore, the required joint geometry can make friction welding and explosive welding difficult to apply.

Based on the foregoing analysis, it is likely to prevent the formation of Ti-Fe intermetallics in the welding if the interlayer is not completely melted. In the meantime, laser welding, as an efficient and flexible non-contact welding technology, has made major achievements in the connection of refractory materials and dissimilar materials. Accordingly, laser served as the welding heat source of Ti alloy and SS. As mentioned earlier, the prepare process of diffusion welding is complicated, and the welding process takes a long time and is inefficient. Therefore, using the advantages of laser welding energy density concentration, controllability, high efficiency and speed, two welding mechanisms (fusion welding and diffusion welding) are combined to avoid melting and liquid mixing of the base metals during welding, and the advantages of the two welding methods are complementary.

\section{Experimental Procedure}

The base materials used in this experiment were TC4 alloy and 304 SS. Their chemical compositions and physical properties are given in Table 1, Table 2 and Table 3. It can be seen that there are large differ-

Table 1: Main chemical compositions of 304 stainless steel (at.\%).

\begin{tabular}{|l|l|l|l|l|l|l|l|}
\hline $\mathrm{Si}$ & $\mathrm{Mn}$ & $\mathrm{P}$ & $\mathrm{S}$ & $\mathrm{Cr}$ & $\mathrm{Ni}$ & $\mathrm{N}$ & $\mathrm{Fe}$ \\
\hline 0.53 & 1.07 & 0.04 & 0.03 & 18.09 & 8.01 & 0.03 & $\mathrm{Bal}$ \\
\hline
\end{tabular}

Table 2: Main chemical compositions of TC4 Titanium alloy (at.\%).

\begin{tabular}{|l|l|l|l|l|l|l|l|}
\hline Al & V & Fe & C & N & H & O & Ti \\
\hline 6.06 & 4.03 & 0.15 & 0.02 & 0.02 & 0.006 & 0.17 & Bal \\
\hline
\end{tabular}

Table 3: Physical properties of TC4 Titanium alloy and 304 stainless steel.

\begin{tabular}{|l|l|l|l|l|l|}
\hline Material & $\begin{array}{l}\text { Melting } \\
\text { point } /{ }^{\circ} \mathrm{C}\end{array}$ & $\begin{array}{l}\text { Practical tensile } \\
\text { strength/MPa }\end{array}$ & $\begin{array}{l}\text { Specific heat capacity/ } \\
\left(\mathrm{J} \cdot \mathrm{kg}^{-1} \cdot \mathrm{K}^{-1}\right)\end{array}$ & $\begin{array}{l}\text { Thermal conductivity/ } \\
\left(\mathrm{W} \cdot \mathrm{m}^{-1} \cdot \mathrm{K}^{-1}\right)\end{array}$ & $\begin{array}{l}\text { Linear expansion } \\
\text { coefficient }\left(10^{-6} \mathrm{~K}^{-1}\right)\end{array}$ \\
\hline TC4 & 1650 & 1100 & 536 & 6.4 & 8.7 \\
\hline 304 & 1454 & 685 & 500 & 16.3 & 17.2 \\
\hline
\end{tabular}


ences in thermal conductivity and linear expansion coefficient between the two base materials, which would lead to large temperature gradient and thermal stress in the joint during welding process. The specimens for direct welding experiments were machined into $100 \mathrm{~mm} \times 80 \mathrm{~mm} \times 1 \mathrm{~mm}$ plates. The filler metal used was $0.5 \mathrm{~mm}$ Ni plate. Before welding, the specimens were mechanically and chemically cleaned. The gap between the edges of the $\mathrm{Ti}$ alloy and SS was very important to adequate heat transfer and prevent porosity formation. The specimens are clamped each other tightly in order to get the minimum gap formation between the edges. CW laser was used with average power of 1.20 $\mathrm{kW}$, wavelength of $1080 \mathrm{~nm}$ and beam spot diameter of $0.1 \mathrm{~mm}$. A schematic diagram of the welding procedure is shown in Figure 1. In order to ensure that $\mathrm{Ni}$ was not completely melted, the laser beam was focused on the SS plate $0.5 \mathrm{~mm}$ away from the SS interface. The welding parameters were: laser beam power of $456 \mathrm{~W}$, defocusing distance of +5 $\mathrm{mm}$, welding speed of $650 \mathrm{~mm} / \mathrm{min}$. Argon gas with the purity of $99.99 \%$ was applied as a shielding gas with total flow of $20 \mathrm{~L} / \mathrm{min}$ at top of the joint.

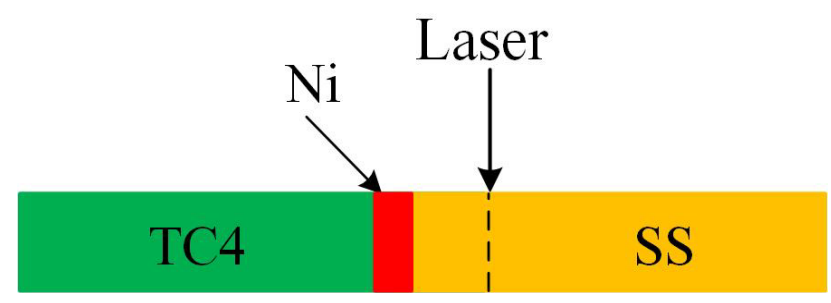

Figure 1: Schematic diagram of the welding process.
Specimens for microstructural characterization were prepared metallographically and then etched using a reagent containing $2 \mathrm{ml} \mathrm{HNO}_{3}$ and $6 \mathrm{ml} \mathrm{HF}$. The microstructure of joints were studied by optical microscopy (Scope Axio ZEISS), scanning electron microscope SEM (S-3400) with fast energy dispersion spectrum EDS analyzer and selected area XRD ( $X$ 'Pert3 Powder) analysis. The operating voltage of XRD was $15 \mathrm{kV}$ and the current was $20 \mathrm{~mA}$ using a $\mathrm{Cu}$ target. Scanning span was $20^{\circ}-90^{\circ}(2 \vartheta)$ with a speed of $3^{\circ}$ per minute. The tensile strength of the joints was evaluated at room temperature in tensile testing machine (MTS Insight $10 \mathrm{kN}$ ) at a cross head speed of $0.2 \mathrm{~mm} / \mathrm{min}$.

\section{Results and Discussion}

The Optical Microscope (OM) image of the cross section of the joint is shown in the Figure 2a. It was found that three regions were formed at the joint, namely, the weld zone of Ni-SS interface, the unmelted $\mathrm{Ni}$ and the reaction layer of $\mathrm{Ti}$ alloy- $\mathrm{Ni}$ interface. The formation of Ti-Fe intermetallics was not found in the weld zone, which was attributed to the presence of unmelted $\mathrm{Ni}$. Because the microstructure of the weld zone at Ni-SS interface is quite different from that of the reaction layer at $\mathrm{Ti}$ alloy-Ni interface, the reaction layer becomes black after corrosion. Figure $2 \mathrm{~b}$ presents the optical microscopy image before corrosion of the $\mathrm{Ti}$ alloy-Ni interface. It does not present such defects as pores and macro-cracks. In addition, unmelted $\mathrm{Ni}$ was beneficial to release and adjust the thermal stress of $\mathrm{Ti}$ alloy-SS joint, thus improving the mechanical properties of the joint. The physical model of the
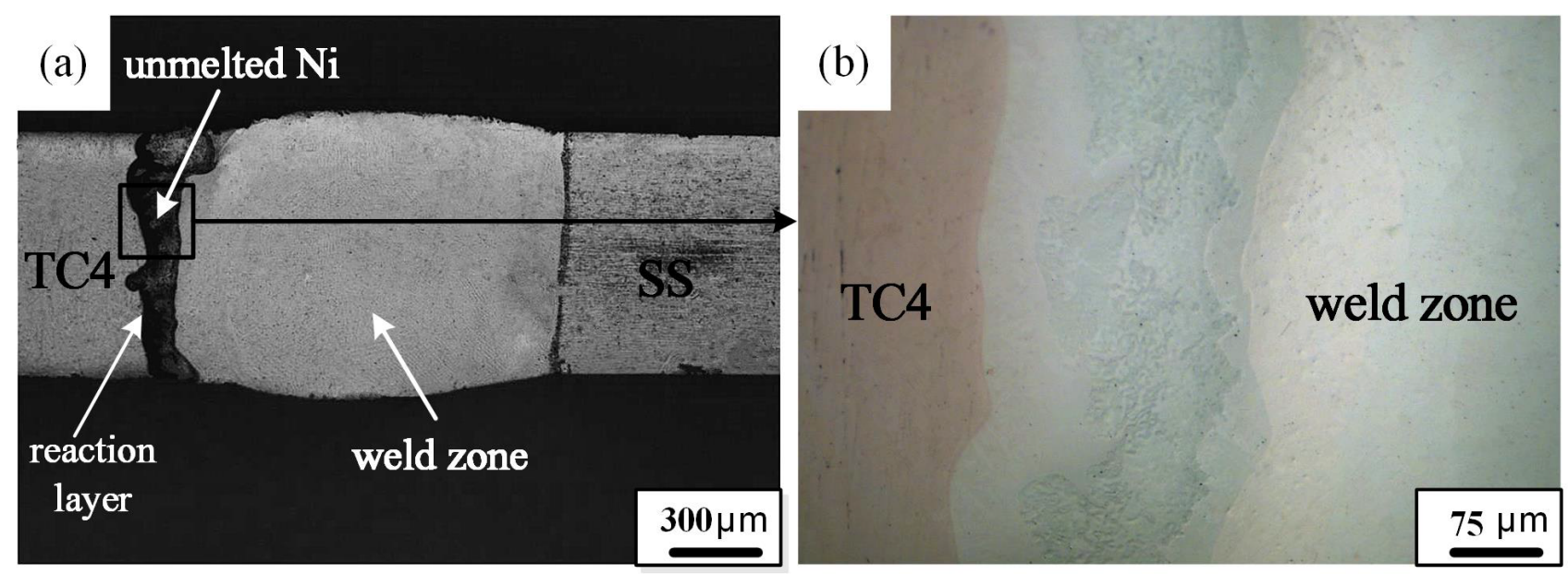

Figure 2: Cross-sections of the joint by laser welding: (a) Optical image of the cross section of the joint; (b) Optical image before corrosion of the Ti alloy-Ni interface. 

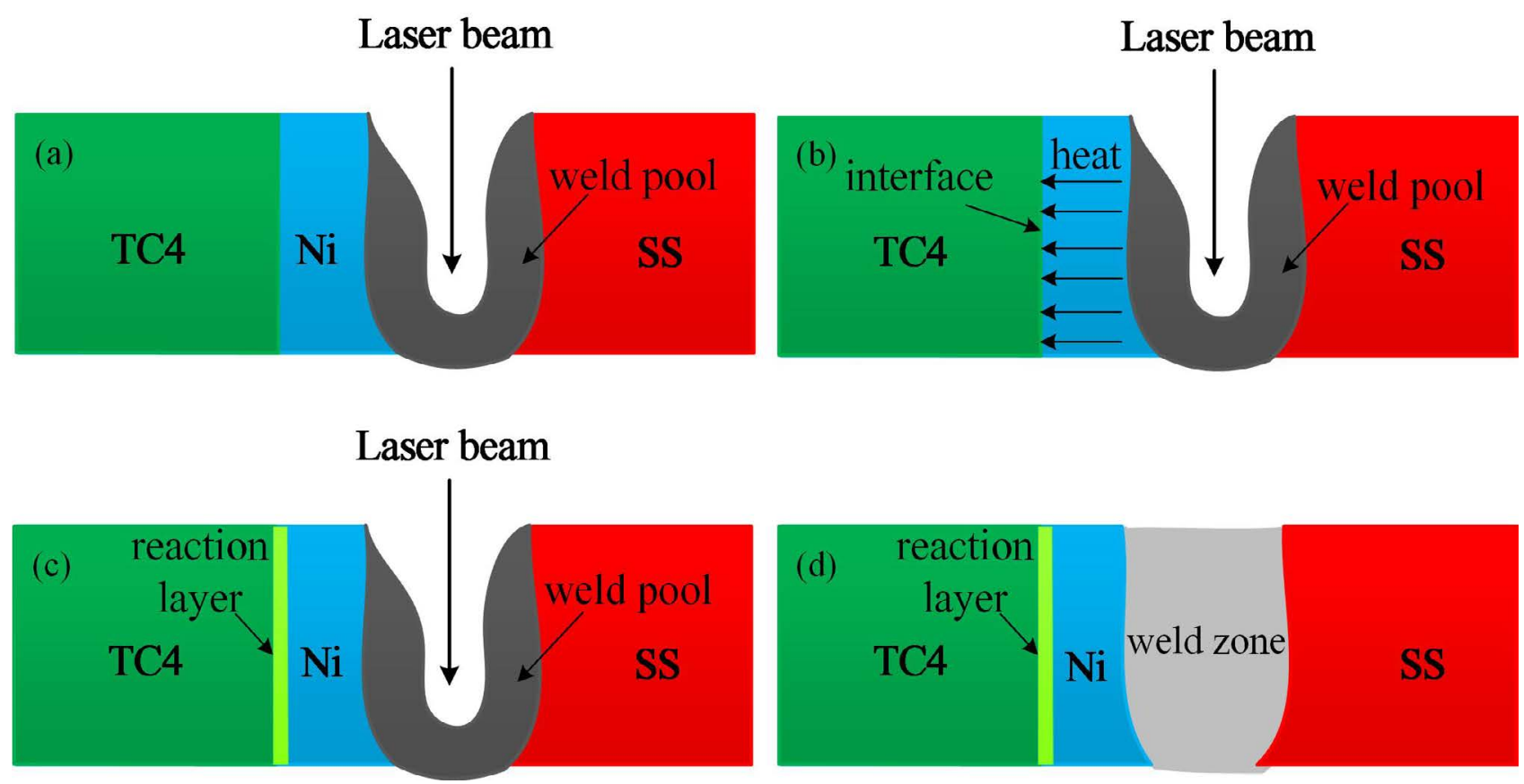

Figure 3: Physical model formation of the joint by laser focused on SS side.

Table 4: EDS analysis of different zones in the joint.

\begin{tabular}{|l|l|l|l|l|l|l|l|l|}
\hline \multirow{2}{*}{ Region } & \multicolumn{9}{l|}{ Composition (wt.\%) } & \multicolumn{2}{l|}{ Potential phases } \\
\cline { 2 - 9 } & $\mathrm{V}$ & $\mathrm{Al}$ & $\mathrm{Ti}$ & $\mathrm{Ni}$ & $\mathrm{Fe}$ & $\mathrm{Ni}$ & $\mathrm{Cr}$ & \\
\hline A & & & & 27.2 & 57.2 & 2.1 & 13.5 & $(\gamma \mathrm{Fe}, \mathrm{Ni})$ \\
\hline G & 2.0 & 4.3 & 46.1 & 47.6 & & & & $\mathrm{TiNi}^{+} \mathrm{TiNi}_{3}$ \\
\hline
\end{tabular}

joint formation is shown in Figure 3. The laser beam was focused on the side of the SS plate, resulting into producing a molten pool with small holes inside the SS and Ni plate and absorbing a lot of heat (Figure 3a). Thus, the edge of the $\mathrm{Ni}$ as the keyhole boundary melted sharply due to the high absorption of the laser inside the keyhole. The unmelted part of Ni interlayer absorbing a significant amount of heat from the welding pool and transferring it to the $\mathrm{Ti}$ alloy side [15]. Hence, the interdiffusion of $\mathrm{Ti}$ and $\mathrm{Ni}$ atoms at $\mathrm{Ti}$ alloy-Ni interface could be promoted due to the high temperature of unmelted $\mathrm{Ni}$ (Figure 3b). In Figure 3c, metallurgical reaction occurred at $\mathrm{Ti}$ alloy-Ni interface to produce reaction layer. Because of the high thermal conductivity of SS, solidification of weld pool and liquid in the joint started from SS side, which could form a mixed joint between welding zone and reaction layer, as shown in Figure $3 c$ and Figure $3 d$.

It should be noted that precise control of the laser spot position is crucial to obtain a sound joint. If the laser spot is far away from the Ni-SS interface, metallurgical reaction of $\mathrm{Ti}$ and $\mathrm{Ni}$ at the $\mathrm{Ti}$ alloy- $\mathrm{Ni}$ interface cannot take place. If the laser spot is draw near to the Ni-SS interface, the $\mathrm{Ni}$ interlayer is beginning to melt in the joint, thereby amount of brittle Ti-Fe intermetallics is greatly increased in the joint and cannot be realized the effective combination between dissimilar materials of Ti alloy and SS.

The OM image of the weld zone is shown in Figure $4 a$ and no defects were observed in it. The cellular dendritic structure was well evident in weld zone. The main chemical composition of weld zone (see Table 4) was nearly 57.2 wt.\% Fe and 27.2 wt.\% Ni. In accordance with the Ni-Fe binary phase diagram, the primary microstructure of weld zone was $(\gamma \mathrm{Fe}, \mathrm{Ni})$ solid solution. In the weld zone, the columnar grain that grows in the center of the weld is located near the fusion line of the two sides, and there are small cell crystal areas in the welding center (Figure 4b). The OM image of reaction layer at $\mathrm{Ti}$ alloy-Ni interface is shown in Figure 4c. It was indicated that the reaction layer was a layered structure. The SEM image of the reaction layer is 
(a)

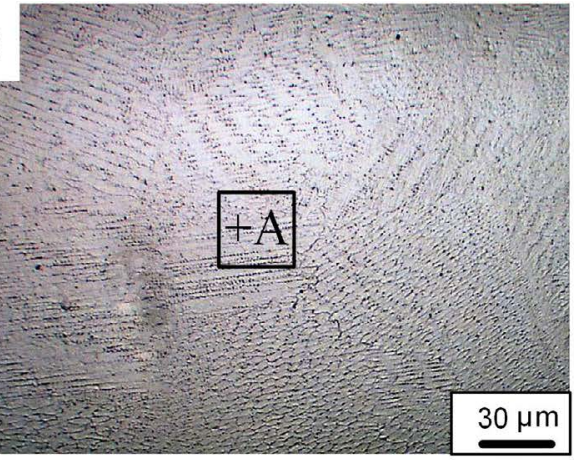

\section{(c)}

(c)

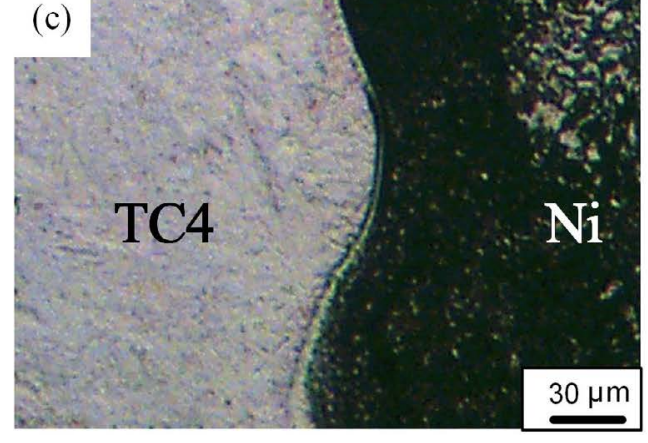

(b)

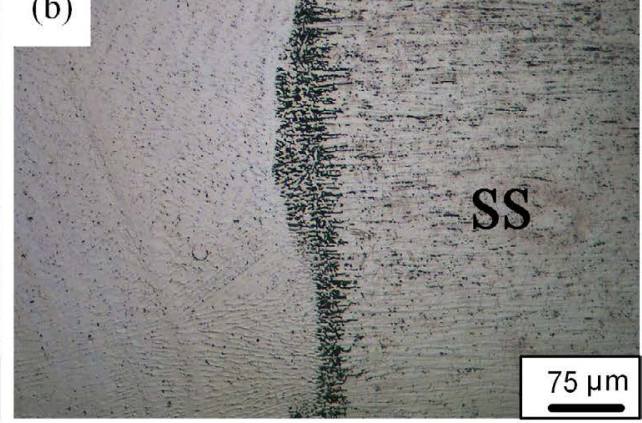

(d)

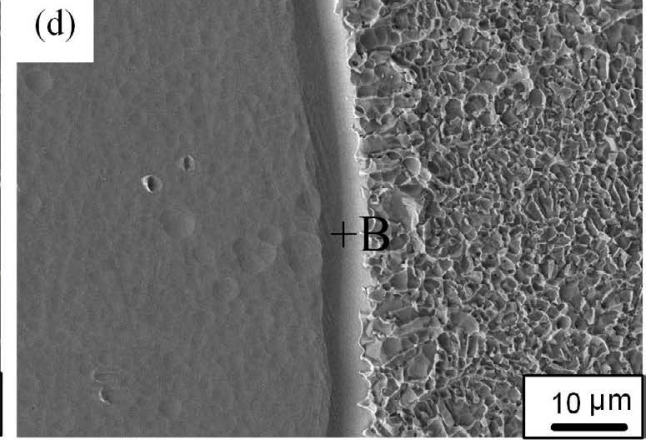

Figure 4: Microstructures of the joint: (a) Optical image of the weld zone; (b) Optical image of the fusion line near SS side; (c) Optical image of the reaction layer; (d) SEM image of the reaction layer.

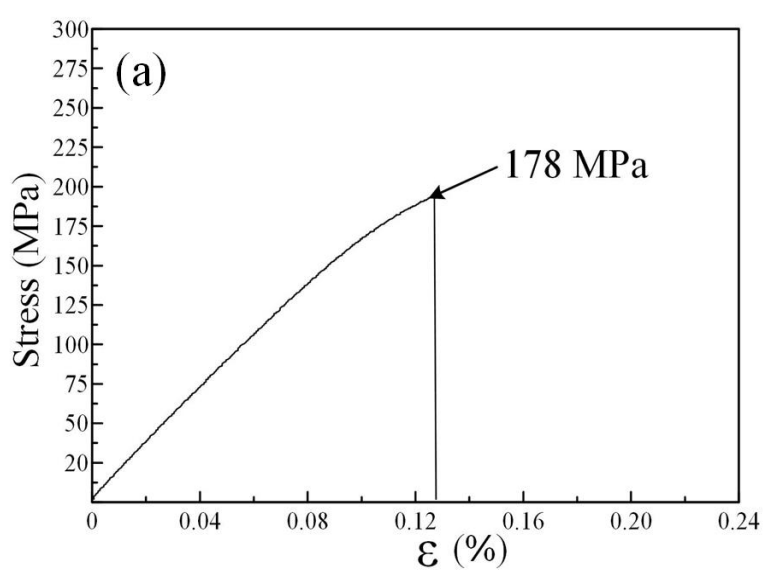

(b)
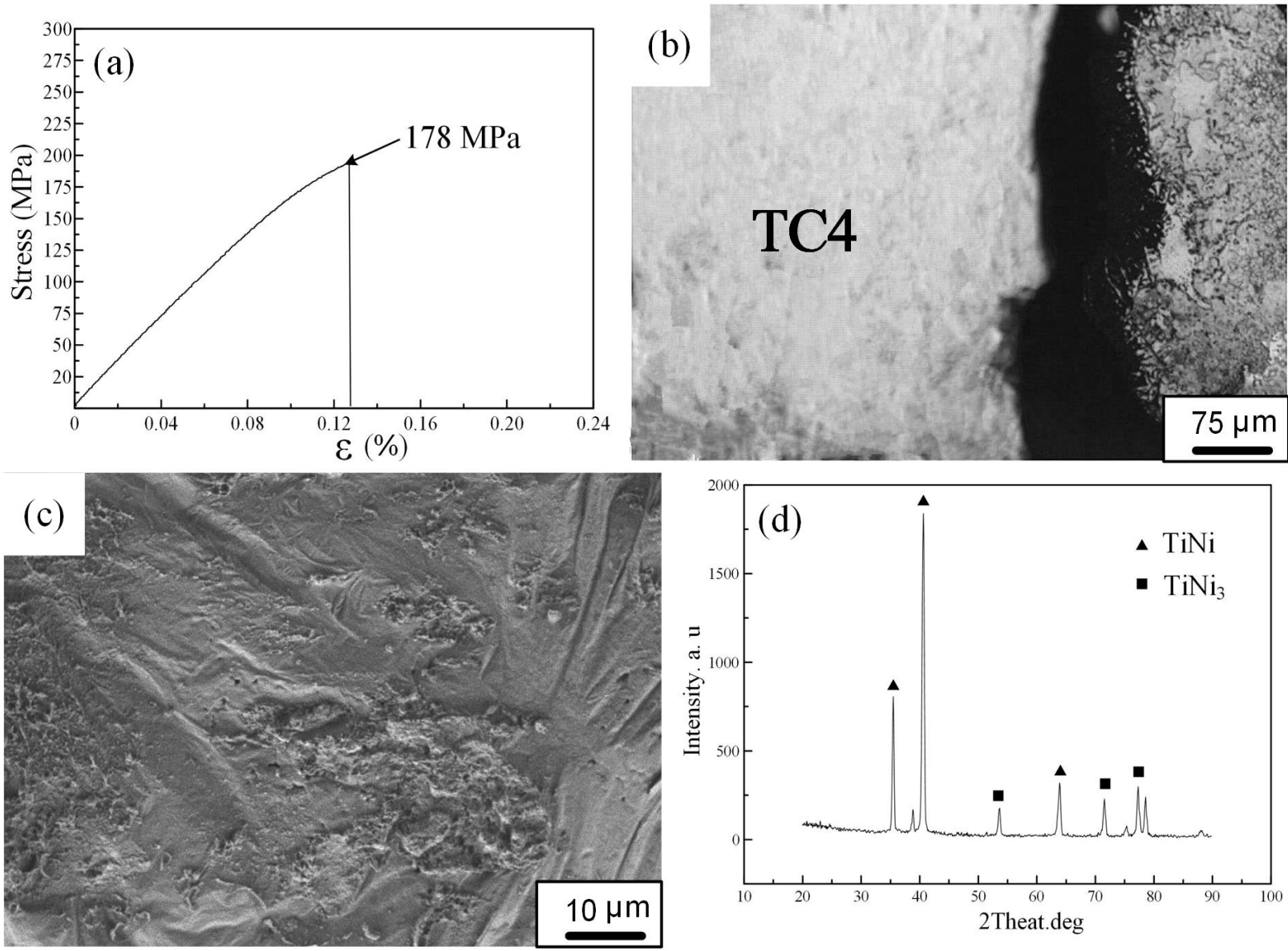

Figure 5: Tensile test results and fracture analysis of the joint: (a) Tensile test curve; (b) Fracture location; (c) SEM image of fracture surface; (d) XRD analysis results of fracture surface. 
shown in Figure 4d. According to EDS analysis results in Table 4, main composition in reaction layer was of 56.1 wt.\% of $\mathrm{Ti}$ and 44.0 wt.\% of $\mathrm{Ni}$. Based on the EDS analyses results and Ti-Ni binary phase diagram, the main microstructure of reaction layer was defined as $\mathrm{TiNi}+\mathrm{TiNi}_{3}$ phase. The width of the reaction layer was $3.4 \mu \mathrm{m}$. According to metal physics knowledge, the greater the thickness of the reaction zone, the greater the cumulative brittleness of the reaction zone [16]. In addition, the high cooling rate inhibited the growth of dendritic structures in the reaction layer. Therefore, a fine dendritic structure was obtained in the reaction layer, which contributed to the minimum brittleness of the reaction layer, thereby improving the mechanical properties of the joint.

The maximum tensile strength of the joint was about $178 \mathrm{MPa}$ (Figure 5a). The joint fractured reaction layer at $\mathrm{Ti}$ alloy- $\mathrm{Ni}$ interface during tensile tests (Figure $5 b$ ). Figure $5 c$ shows fracture surface of the joint exhibiting typical brittle characteristics. Moreover, as shown in Figure $5 d$, XRD analyses of fracture surface detected $\mathrm{TiNi}$ and $\mathrm{TiNi}_{3}$ phases. This confirmed the presence of Ti-Ni intermetallics at fracture surfaces. It should be noted that there was no Ti-Fe intermetallics in the weld zone and reaction layer. The reaction layer at $\mathrm{Ti}$ alloy- $\mathrm{Ni}$ interface became the weak zone of the joint, which led to the failure in the tensile test.

\section{Conclusions}

Dissimilar laser welding of $\mathrm{Ti}$ alloy to SS was achieved using a Ni interlayer. Unmelted $\mathrm{Ni}$ interlayer acted as a barrier to mixing of the two base materials, which prevented the formation of brittle Ti-Fe intermetallics, while ensuring joining at both interfaces. At the Ni-SS interface, a weld zone formed by fusion welding. No intermetallics except for $(\gamma \mathrm{Fe}, \mathrm{Ni})$ solid solution were produced in the weld zone and cellular dendritic structure was observed. At the Ti alloy-Ni interface, a reaction layer formed by metallurgical reaction. The reaction layer mainly contained $\mathrm{TiNi}$ and $\mathrm{TiNi}_{3}$. The tensile strength can reach to $178 \mathrm{MPa}$.

\section{References}

1. M Gao, SW Mei (2012) Characterisation of laser welded dissimilar Ti/steel joint using Mg interlayer. Sci Technol Weld Join 17: 269-276.

2. I Tomashchuk, P Sallamand, H Andrzejewski, D Grevey (2011) The formation of intermetallics in dis- similar Ti6AI4V/copper/AISI 316L electron beam and Nd:YAG laser joints. Intermetallics 19: 1466-1473.

3. Pilling J (1988) The kinetics of isostatic diffusion bonding in superplastic materials. Mater Sci Eng 100: 137-144.

4. X Changqing, J Zangpeng (1990) The evolution of microstructure and diffusion paths in the titanium-steel explosion weld interface during heat treatment. J Less Common Mater 162: 315-322.

5. Youmin Rong, Jiajun Xu, Ting Lei, Yu Huang, Xinyu Shao, et al. (2018) Magnetism aided mitigation of deformation and residual stress in dissimilar joint 316L with EH36. Journal of Materials Processing Technology 259: 23-32.

6. Jinglin Liu, Shiyu Niu, Rong Ren, Shude Ji, Lei Wang (2019) Improving joint morphologies and tensile strength of $\mathrm{Al} / \mathrm{Mg}$ dissimilar alloys friction stir lap welding by changing $\mathrm{zn}$ interlayer thickness. Acta Metallurgica Sinica 32: 1385-1395.

7. Dong HG, Yang ZL, Wang ZR, Deng DW, Dong C (2014) Vacuum brazing TC4 Ti alloy to 304 stainless steel with $\mathrm{Cu}-\mathrm{Ti}-\mathrm{Ni}-\mathrm{Zr}-\mathrm{V}$ amorphous alloy. Journal of Materials Engineering and Performance 23: 3770-3777.

8. Li HM, Sun DQ, Dong P, Wang WQ, Yin SQ (2011) Study on laser welding of dissimilar materials between TiNi shape memory alloy/stainless steel. J Mater Eng Perform 10: 47-52.

9. Youmin Rong, Jiajun $\mathrm{Xu}$, Ting Lei, Wenbin Wang, Ahmed Adil Sabbar, et al. (2018) Microstructure and alloy element distribution of dissimilar joint $316 \mathrm{~L}$ and EH36 in laser welding. Science \& Technology of Welding \& Joining 23: 454-461.

10.Y Zhang, DQ Sun, XY Gu, HM Li (2016) A hybrid joint based on two kinds of bonding mechanisms for Titanium alloy and stainless steel by pulsed laser welding. Materials Letters 185: 152-155.

11.Y Zhang, DQ Sun, XY Gu, HM Li (2018) Nd:YAG pulsed laser welding of dissimilar metals of titanium alloy to stainless steel. Int J Adv Manuf Technol 94: 10731085.

12.S Kundu, M Ghosh, A Laik, K Bhanumurthy, GB Kale, et al. (2005) Diffusion boning of commercially pure titanium to 304 stainless steel using copper interlayer. Mater Sci Eng A 407: 154-160.

13.M Fazel-Najafabadi, SF Kashani-Bozorg, A Zarei-Hanzaki (2010) Joining of CP-Ti to 304 stainless steel using friction stir welding technique. Mater Des 31: 4800-4807.

14.SA Mousavi, PF Sartangi (2009) Experimental inves- 
tigation of explosive welding of Cp-titanium/AISI 304 Stainless steel. Mater Des 30: 459-468.

15.JP Oliveira, B Panton, Z Zeng, CM Andrei, Y Zhou, et al. (2016) Laser joining of NiTi to Ti6Al4V using a Niobium interlayer. Acta Materialia 105: 9-15.
16.BG Zhang, T Wang, GQ Chen, JC Feng (2012) Contact reactive joining of TA15 and 304 stainless steel via a copper interlayer heated by electron beam with a beam deflection. Journal of Materials Engineering and Performance 21: 2067-2073. 